\title{
Zygomatic implant: Late complications in a period of 12 years of experience
}

\author{
Hugo N. Filho ${ }^{1}$, Wilson S. Amaral ${ }^{2}$, Claudia Curra ${ }^{2}$, Camila L. Cardoso ${ }^{3}$, Pâmela L. dos Santos ${ }^{3 *}$
}

\begin{abstract}
1. DDS, MSc, PhD, Chairman, Department of Oral and Maxillofacial Surgery, University of Sagrado Coração, Bauru, São Paulo, Brazil

2. DDS, MSc-Student, Department of Oral and Maxillofacial Surgery, University of Sagrado

Coração, Bauru, São Paulo, Brazil

3. DDS, MSc, PhD, Assistant Professor,

Department of Oral and Maxillofacial Surgery,

University of Sagrado Coração, Bauru, São Paulo, Brazil
\end{abstract}

*Correspondencia a: pamelalsantos@hotmail.com Trabajo recibido el 28/10/2015. Aprobado para su publicación el 08/03/2016

\begin{abstract}
Purpose Zygomatic implants (ZI) constitute a suitable alternative for treating severe maxillary atrophy. However, a large number of complications associated with ZI have been reported in the literature. This paper presents the late complications associated with ZI during 12 years of experience in the same institution.

Materials and methods All cases of Zl from 2000 to 2013 were retrospectively evaluated and the major complications relating to this type of rehabilitation were selected to report. Results The major complications found were: loss of implant, loss of osseointegration, bucco-sinusal communication, fenestration of alveolar mucosa, sinus pathology, and emergency palate fixations.

Conclusion The clinical experience of the dental surgeon is critical in the success of zygomatic fixation. Furthermore, there should be careful planning of rehabilitation to reduce the rate of complications.

KEYWORDS

Zygomatic implant; Zygomatic fixation; Complications
\end{abstract}

Rev. Clin. Periodoncia Implantol. Rehabil. Oral Vol. 10(3); 176-179, 2017.

\section{INTRODUCTION}

Since the first description, in 1998, ${ }^{(1)}$ the rehabilitation using the zygomatic implants (ZI) suffered technical modifications over the years, however the indications remained the same: repair the functional aspect of mutilated patients or in cases of severely resorbed maxillae, which makes difficult to install the conventional fixation..$^{(2-4)}$ The great advantage of this type of rehabilitation is not only to minimize postoperative morbidity caused by reconstructive surgeries, but also to eliminate hospitalization, high cost and risk of complications. Over the years, it was proposed a modification of technique using just four ZI, mainly when the pre-maxilla presents severely resorbed. ${ }^{(3-5)}$ Then, with increasing indication, it also increases the complication rate.

Generally, the complications from zygomatic fixation may be divided in immediate and late. The immediate complications are related to post-operative and it is associated with the surgeon experience, the technique applied, the anatomical condition and the individual aspects. Examples of immediate complications are: periorbital and conjunctiva hematoma, nosebleed, paresthesia and burns on the skin or labia mucosa. Those complications have a good prognosis. On the other hand, the late complications require a carefully therapy, considering the anatomical site. Some examples of late complication are: loss of fixation or osseointegration, bucco sinusal communication, fenestration of the buccal mucosa, chronic sinusitis and sinus pathologies, palata emergency of fixations, mucositis and peri-implantitis. ${ }^{(6-14)}$

Recent systematic review studies reported the survival and presence of complications related of zygomatic fixation. ${ }^{(15)}$ They conclude that the studies with a high level of evidence are scarce. ${ }^{(15)}$ Here in, we report late complications related to rehabilitation of the atrophic maxilla, using zygomatic fixations, during 12 years of experience.

\section{MATERIAL AND METHODS}

It was performed a retrospectively study in all cases of ZI rehabilitation (from 2000 to 2013), in the same institution (University Sagrado Coração, Bauru, São Paulo, Brazil). It was selected only the major complications which occurred in this period.

All cases evaluated were previously selected, discussed and prepared surgically by the team. Imaging examination and guides were used to the surgical planning. The post-operative follow up was minutely conducted over the years.

\section{RESULTS}

Late complications

Loss of fixation

Loss of the zygomatic fixation may occur as observed in conventional implants. The zygomatic fixation presents few areas of bone contact along the entire fixation, restricting to some millimeters in the alveolar region and zygomatic bone implantation site. Therefore, it should be found the maximum bone contact between the implant and the zygomatic process of the maxilla. The adoption of techniques of externalization and use of maxillary zygomatic process may provide greater contact area. However, both the classical technique and the externalization may present advantages and disadvantages. The classical technique protects more the fixation, reduces the bone contact area and predisposes occurrence of maxillary sinus complications. The exteriorization presents greater technical facility and greater anchorage, therefore it may result an important periimplant involvement, buccal recessions and difficult control of oral hygiene. In addition, the extensive bone destruction followed the loss of fixation should be considered (Figs. 1 and 2). It is important to consider that the loss of osseointegration in alveolar portion (in the conventional technique) does not mean loss of implant, except when it is associated in a rotational movement and painful symptoms. However, when a buccosinusal communication is established, the implant must be removed, even if it was osseointegrated in the zygomatic bone.

Loss of osseointegration with or without buccosinusal communication

In the loss of osseointegration, is really important the investigation of the presence of fistulas. It is important to consider the symptomatology to evaluate the success of the implant, even though it is osseointegrated. If the implant has limited mobility, but ausence of pain and sinusitis, it is possible keep it in function in mutilated patients. If the case evolves unsatisfactorily, the buccosinusal communication (BSC) is maintained through a fistula. In this case, the implant must be removed, because it can be a way to contamination. Moving an implant can involve force and also an osteotomy of zygomatic bone resulting in bone loss of alveolar region. It is essential to reestablish the integrity of maxillary sinus, using grafts and techniques of flap rotation to enable the resolution of BSC. Later, a reconstructive procedure may be indicated to try another zygomatic anchorage.

\section{Fenestration of alveolar mucosa}

Because of the cases with severe alveolar resorption, including in the maxillary zygomatic pillar, the fenestration of the alveolar mucosa may 
occur, creating a retraction of the mucosa and exposure thread of the implant (Fig. 3). If it is possible, the fixation must be maintained inside the maxillary sinus, preserving the zygomatic process, an important anatomic repair to the treatment of complications and loss of zygomatic implants. This detail is more important when the patient presents a ridge with a little loss in height, because the muscle insertion of deep sulcus is farthest, resulting in gingival retractions. In cases of maxillary atrophy, where the muscle insertion is maintained close of the ridge, the fenestrations are protected, as in mutilated patients without alveolar portion and the implant is placed with great fenestration. The treatment of this late complication is impracticable and the biggest difficulty is to control the bacterial plaque, which is more difficult than in conventional situations. It is noteworthy the importance of certifying the absence of BSC and periodic follow-up should be done to evaluate the periimplant condition.

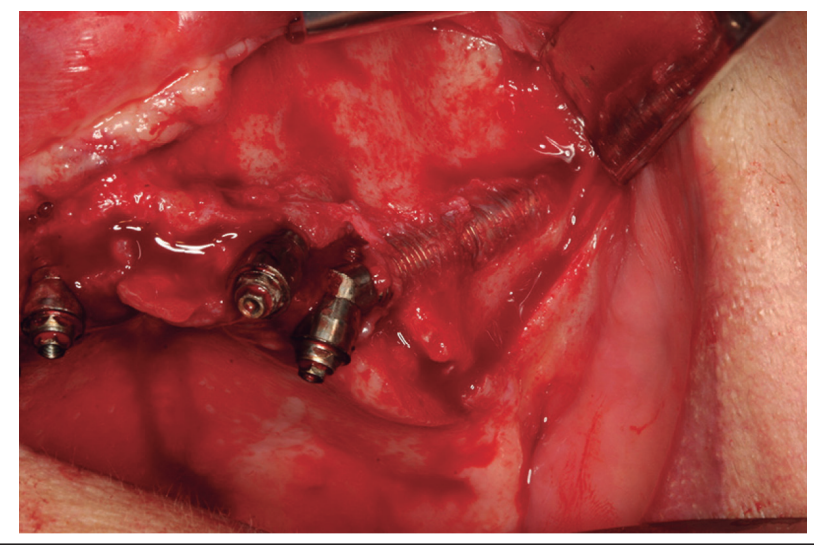

Figure 1. Alveolar fenestration and loss of zygomatic fixation.

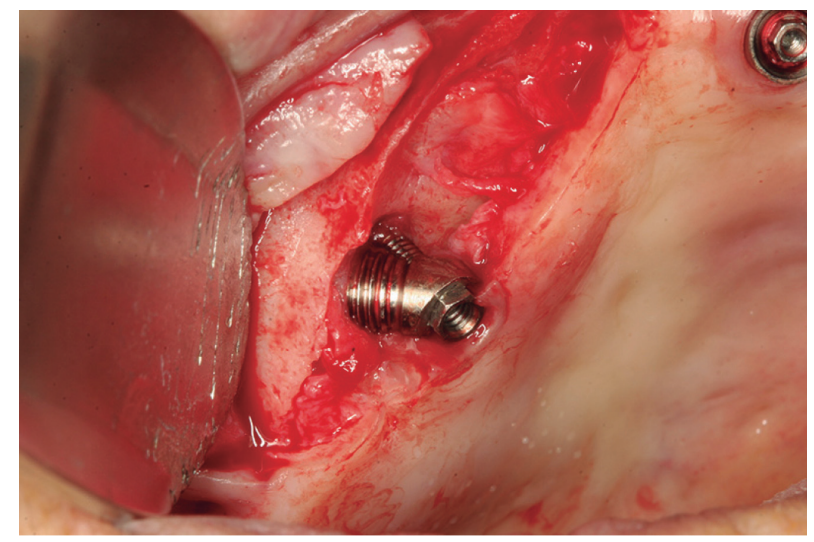

Figure 2. Bone loss due to the screw hole prosthetic.

\section{Sinus pathology}

The presence of sinus pathology should be detected early, since the medical history, to avoid late complications associated with the implants. Chronical sinusitis, allergic episodes or other sinus pathologies deserve preview multidisciplinary approach with otorhinolaryngologist. Sinus approach, through of a bone window with rupture or removal sinusal membrane is controversial. The access and removal of sinusal membrane, allowing view and irrigation during the insertion of the implant are justified. Besides, they offer access to sinusal pathologies like polyps or cysts eventually find inside the maxillary sinus (Fig. 4).

\section{Palatal emergency of fixations}

Attempts of changing protocol, through the buccal approaches, change in implant design, change of incline of implant head or use new intermediates, aim to optimize the rehabilitation, both phonetically as in the biomechanics of the system..$^{(1-3)}$ Maxillae with large buccal concavity and transversal atresia restrict the results obtained in this techniques. In favorable situations, with enough bone, these technical changes offer little benefit compared to the original protocol, because both are performed in situations of good prognosis. In cases of facial deformities and big atresias, the buccal approaches are interesting, since it does not exist the possibility of alveolar anchoring. ${ }^{(4)}$ This are borderline cases, where there is not the best option to treatment, even considering the risks. In the conventional cases, the alveolar anchoring is very important and must be considered (Figs. 5 and 6).

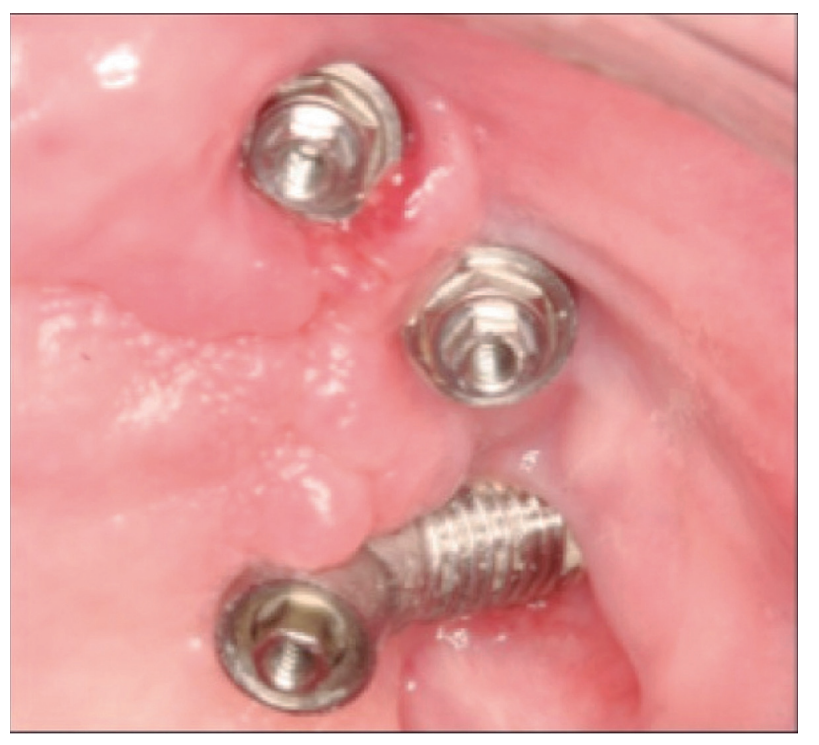

Figure 3. Fenestration resulting from external access.

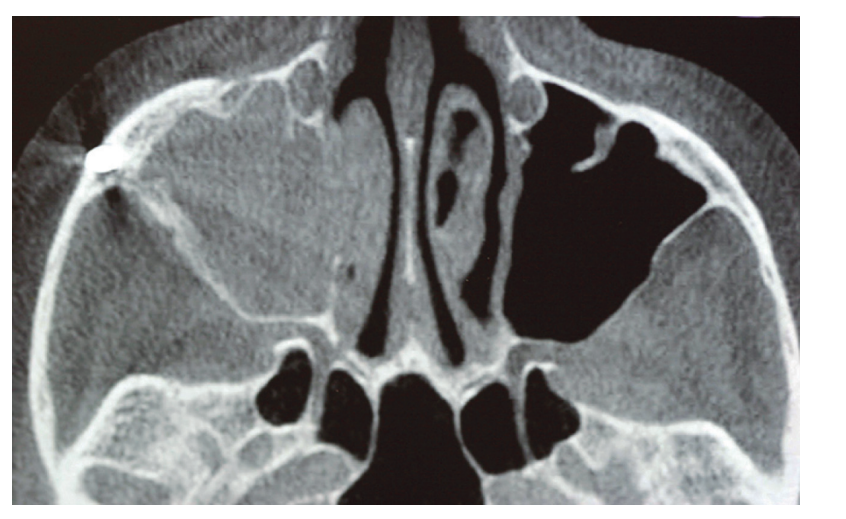

Figure 4. Sinus pathology resulting from zygomatic implant.

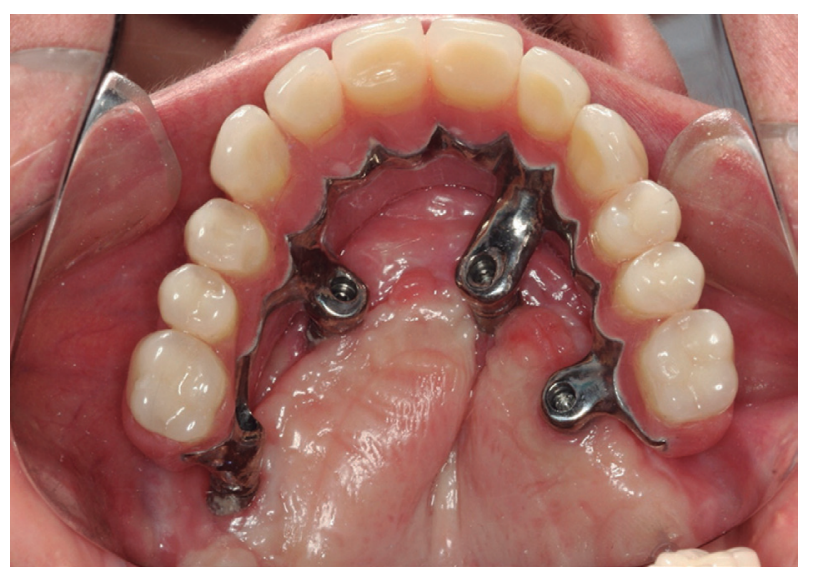

$\overline{\text { Figure 5. Positioning of palatal implants generating a lever arm on the }}$ prosthesis.

\section{Mucositis and periimplantitis}

The condition of normality of periimplant tissue of rehabilitation implant-supported, depends of some factors like: feature of mucosa, type of prosthetic connection, form of convenience of the prosthesis and, specially, the capacity of control of bacterial plaque by the patient. Periimplant changes can appear in any implant, but in zygomatic implants, there are some important differences, which must be considered. Regarding the kind of mucosa, two aspects are important: the volume of mucosa (since gingival margin until the alveolar crest) and its nature. The ideal condition is the positioning of intermediate in keratinized mucosa and the palatal emergency contributes in this case. It is important to 


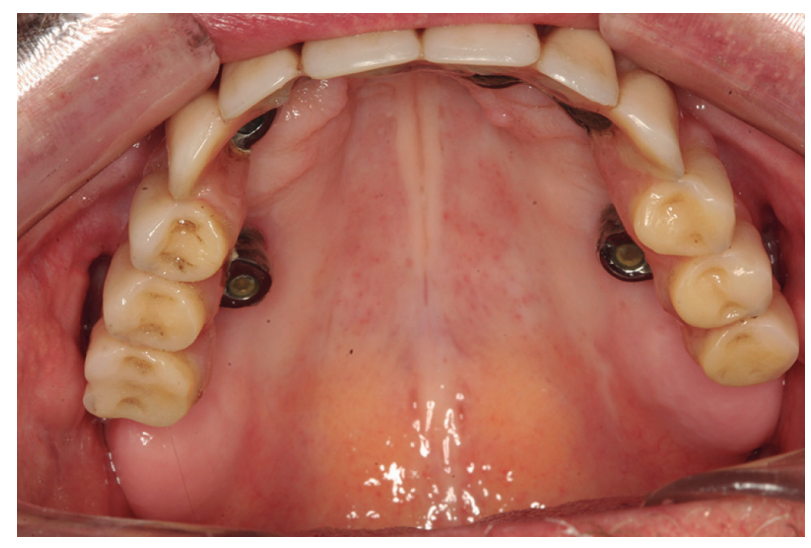

Figure 6. Access palatal of zygomatic implant.

estimate the availability of masticatory mucosa. Found its shortage, the access must include an incision more palatal, that allows a repositioning more buccal of suture and, consequently, improve the periimplant tissue conditions. When the head of the implant is positioned palatally, or there is a big volume of keratinized mucosa, the incision should be applied in buccal. As mentioned, a buccal access, next to the transition of alveola mucosa can allow the achievement of some fenestration, from where the intermediates appeared, far of the incision line. The advantage of this technique includes stability of the retail and absence of risk of dehiscence around of the intermediate, providing a better repair, greater predictability the height of the intermediate selected and greater facility of removal of suture in procedures of immediate loading.

However, not only the quality of the mucosa around the implant is important, but also its thickness. When the wucosa is very thick this implies in deep gingival sulcus, long epithelium and wide area of adaptation conjunctiva. This condition in occurrence of bacterial plaque promotes the formation of inflammatory process and mucositis (Fig. 7) The biological distance corresponds the space in millimeters since the bone crest until the gingival margin, that in case of implant can change from 2 to $3 \mathrm{~mm}$. Thus, the greater the thickness of the mucosa, more chance to occur periimplantar alterations. In palate region, the thickness is different compared to the alveolar crest, related the big quantity of connective tissue, adipose tissue and presence of small salivary glands. Although, must be reduced internally, with scalpel blades help, to limit the thickness to $2-3 \mathrm{~mm}$. In this way, the size of intermediates will decline allowing the exposure of the head of the zygomatic implant. Once it is angled, the zygomatic implant presents $3-4 \mathrm{~mm}$ above the bone level, what would put the connection area with the intermediate above the gingival margin, do not affecting the marginal bone loss.

The incidence of mucositis is considered high. ${ }^{(16)}$ The difficulty to control mucositis can result in an evolution of the disease with bone destruction, featuring periimplantitis, which is a high level when related to zygomatic implant, once the volume alveolar bone is limited. The loss of 2-3mm may result in loss of total bone volume favoring a buccosinusal communication. In addition, bone loss is not related only to the effect of the connection area, but also in biomechanical conditions of plaque control by the patient. Thus, changes in the head of fixation, that eliminate the hole of transfixation of prosthetic screw; the decreasing of the thickness of the mucosa; the manufacturing of prostheses with convenience form that make it difficult to grip fillings and make easier the mechanical contro of the plaque by the patient, these are the essential requirements to the system longevity based in maxillary rehabilitation using zygomatic implant.

\section{DISCUSSION}

Although studies have demonstrated that zygomatic implant is a viable and successful option for rehabilitation of patients with severe maxillary atrophy, the complications of this treatment are being discussed in the recent literature. ${ }^{(15)}$ Recent systematic review, evaluated the level of survival and presence of complications in a period of 12 years. Only 42 studies or clinical cases of zygomatic implant were included in the criteria selection. The cumulative level of survival was about $96.7 \%$, however, the complications related in this studies were: 70 cases of sinusitis, 48 cases of infection of soft tissues, 15 cases of paresthesia and 17 cases of fistula buccosinusal. It is important to note that the most of the studies evaluated did not show if had or not any complication. Finally, the authors conclude the necessity of more studies with a long period of follow up. ${ }^{(15)}$

In relation to the access, the opening of anterior wall, as practiced

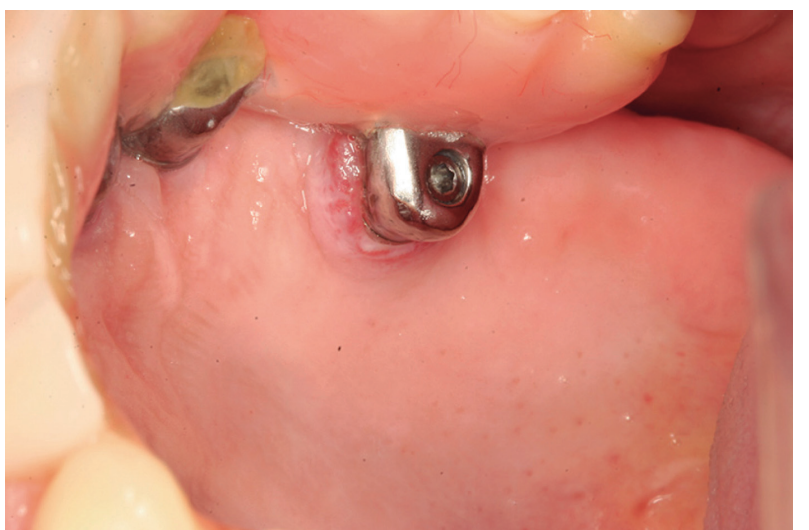

Figure 7. Mucositis caused by zygomatic implant.

by the Caldwell Luc technique, contribute to more risk of complication postoperative as sensorial alterations, penetration of soft tissue inside of the sinus, creating sinusitis and other pathologies like surgical cysts. $(17,18)$ However, authors showed the absence of the relation of the opening of anterior wall, in this surgery, with complications. ${ }^{(19)}$ More than that showed through of sinuscopia the perfect harmony of the implant inside of maxillary sinus with normal mucosa around the fixations.

To the safety that the practical of the opening of anterior wall offers to the operator, allowing a good control of the directing of the milling and installation of the fixation seems a very indicated attitude, especially to surgeons with less experience. If it is possible, the sinusal membrane must be preserved.

It is important to highlight that what is understood by zygomatic fixation with a long period of control, comes from the operated cases with a classical technique, using the osteotomy of the anterior wall, without any care with the membrane and with no reposition of the buccal bone plate as suggested here. ${ }^{(20-23,10)}$ Thus, technique and procedures mentioned here represent tendencies to optimize the good results obtained with this dedicated system.

For some authors, the palatal emergency of the fixations is the biggest problem of this technique for providing a palatal positioning of the head of the implant. There is a study that this emergency could induce phonetic changes and specially some local discomfort to the patient. This worry appears in attempts to change the protocol, with buccal approaches ${ }^{(1,2)}$ change in the draw of the implant, ${ }^{(3)}$ with modification of the bending of its head or even new intermediates. ${ }^{(24)}$ Though, the reasons above cannot justify this tests, once that a reduced number of patients presents this complaint. Perhaps, the main reasons to get an optimization of the positioning of the zygomatic fixation, are related to biomechanics of the prostheses in an attempt of reduce the side offsets, and so gets more control of hygiene by the patient. Thus, is important the efforts in this way, but the bone anatomy keep being the biggest problem to the ideal location of the implant. ${ }^{(19,25)}$

There are still some complications in this technique. The hard access, as the instruments used make lacerations in the lips and a bad postoperative. It is important to remember that as all implants, they must be installed in a good positioning for the biomechanical system. The small area of anchoring that is allowed in the zygomatic bone is also a technical disabilities, because this stays anchored just in an apical portion, what provides a lever that committed the long life of rehabilitations.

Here in, the same complications found in the literature were discussed. The immediate complications usually are associated by the technique. The late complications like sinusitis, inflammation of periimplant soft tissue and paresthesia are commonly found in the literature. The zygomatic fixation not only depends of the surgeon's experience but also has limitations. The limitations and indications should be understood in an attempt to optimize rehabilitation and reduce complications. For that, a careful planning must be performed.

\section{CONFLICT OF INTEREST}

The authors declare no conflict of interest. 


\section{References}

1. Brånemark PI. Surgery fixture installation. Zygomaticus fixture clinical procedures. 1a ed. Gotemburgo, Suécia: Nobel Biocare, AB; 1998

2. Weicher T, Schettler D, Mohr C. Titanium implants in the zygoma as retaining elements after hemimaxillectomy. Int J Oral Maxillofac Implants. 1997;12:211-4.

3. Stella J, Warner M. Sinus slot technique for simplification and improved orientation of zygomaticus dental implants: a technical note. Int J Oral Maxillofac Implants. 2000;15:889-93. 4. Duarte IR, Nary Filho H, Francischone C. Fixações zigomáticas: uma excelente alternativa cirúrgica para maxila severamente reabsorvida. Revisão de literatura e estágio científico atual. Implant News. 2004;1:477-86.

5. Duarte LR, Peredo LG, Nary Filho H. Reabilitação da maxila atrófica utilizando quatro fixações zigomáticas em sistema de carga imediata. Implant News. 2004;1:45-50.

6. Zwahlen RA, Grätz KW, Oechslin CK, Studer SP. Survival rate of zygomatic implants in atrophic or partially resected maxillae prior to functional loading: a retrospective clinical report. Int J Oral Maxillofac Implants. 2006;21:413-20.

7. Davó R. Zygomatic implants placed with a 2-stage procedure: a 5-year retrospective study. Eur J Oral Implantol. 2009;2:115-24.

8. Kahnberg KE, Henry PJ, Hirsch JM, Ohrnell LO, Andreasson L, Brånemark PI, et al. Clinical evaluation of the zygoma implant: 3 -year follow-up at 16 clinics. J Oral Maxillofac Surg. 2007;65:2033-8

9. Hervé R, Raphael O. Intracerebral penetration of a zygomatic dental implant and consequent therapeutic dilemmas: case report. Int J Oral Maxillofac Implants. 2010;25:416-8. 10. Malevez C, Abarca M, Durdu F, Daelemans P. Clinical outcome of 103 consecutive zygomatic implants: a 6-48 months follow-up study. Clin Oral Implants Res. 2004;15:18-22. 11. Becktor JP, Isaksson S, Abrahamsson P, Sennerby L. Evaluation of 31 zygomatic implants and 74 regular dental implants used in 16 patients for prosthetic reconstruction of the atrophic maxilla with cross-arch fixed bridges. Clin Implant Dent Relat Res. 2005;7:159-65.

12. Landes CA. Zygoma implant-supported midfacial prosthetic rehabilitation: a 4-year followup study including assessment of quality of life. Clin Oral Implants Res. 2005;16:313-25.

13. Aparicio C, Ouazzani W, Garcia R, Arevalo X, Muela R, Fortes V. A prospective clinical study on titanium implants in the zygomatic arch for prosthetic rehabilitation of the atrophic edentulous maxilla with a follow-up of 6 months to 5 years. Clin Implant Dent Relat Res. 2006;8:114-22.
14. Farzad P, Andersson L, Gunnarsson S, Johansson B. Rehabilitation of severely resorbed maxillae with zygomatic implants: an evaluation of implant stability, tissue conditions, and patients' opinion before and after treatment. Int J Oral Maxillofac Implants. 2006;21:399-404. 15. Chrcanovic BR, Abreu MH. Survival and complications of zygomatic implants: a systematic review. Oral Maxillofac Surg. 2013;17:81-93.

16. Al-Nawas Wegener J, Bender C, Wagner W. Critical soft tissue parameters of the zygomatic implants. J Clin Periodontol. 2004;31:497-500.

17. De Freitas J, Lucente FE. The Caldwell-Luc procedure: institutional review of 670 cases 1975-1985. Laryngoscope. 1988;12:1297-300.

18. Ikeda K, Hirano K, Oshima T, Shimomura A, Suzuki H, Sunose H, et al. Comparison of complications between endoscopic sinus surgery and Caldwell-Luc operation. Tohoku J Exp Med. 1996:180:27-31.

19. Petruson B. Sinuscopy in patients with titanium implants in the nose and sinuses. Scand J Plast Reconstr Surg Hand Surg. 2004;38:86-93.

20. Bedrossian E, Tumpel L 3rd, Beckely ML, Indresano T. The zygomatic implants: preliminary data on treatment of severely resorbed maxillae. A clinical report. Int $\mathrm{J}$ Oral Maxillofac Implants. 2002;17:861-5.

21. Brånemark PI, Gröndahl K, Ohrnell LO, Nilsson P, Petruson B, Svensson B, et al Zygoma fixture in the management of advanced atrophy of the maxilla: technique and longterm results. Scand J Plast Reconstr Surg Hand Surg. 2004;38:70-85.

22. Hirsch JM, Ohrnell LO, Henry PJ, Andreasson I, Brånemark PI, Chiapasco MA. Clinical evaluation of the zygoma fixture: one year of follow-up at 16 clinics. J Oral Maxillofac Surg 2004;62:22-9.

23. Jemt T, Lekholm U. Implant treatment in edentulous maxillae: a 5-year follow-up report on patients with different degrees of jaw resorption. Int J Oral Maxillofac Implants. 1995;10: 303-11.

24. Eger DE, Gunsolley JC, Feldman S. Comparison of angled and standard abutment and their effect on clinical outcomes: a preliminary report. Int J Oral Maxillofac Implants. 2000;15: 819-23.

25. Nary Filho H, Ilg JP. Atrofia severa da maxila. In: Dinatto JC, Polido WD, editors Implantes Osseointegrados, Cirurgia e Prótese. São Paulo: Artes Médicas; 2001. p. 343-72. 